\title{
On the Explanatory Value of Individuals and Stages
}

\author{
Commentary on Tafreshi, Khalil, and Racine
}

\author{
David C. Witherington \\ University of New Mexico, Albuquerque, NM, USA
}

\begin{abstract}
Keywords
Person-centered analysis - Stage theory · Formal cause - Final cause - Knowledge development $\cdot$ Personal epistemology
\end{abstract}

As a science, psychology aims to understand and predict the actions of individuals. During the discipline's inaugural years, experimental pioneers like Wundt and Ebbinghaus strove to elucidate regularities in human mental activities by studying persons on a case-by-case basis (Lamiell, 2009). Yet for much of the discipline's history (including the present), insight into the functioning of individuals has routinely derived not from examination of individuals qua individuals but (erroneously) from examination of group-level data - data that statistically fashion a sense of the "average" person to which few individuals readily conform (Lamiell, 2009; Molenaar, 2004; Nesselroade \& Molenaar, 2010). Thankfully, person-centered inquiry, with its spotlight on the person as unit of analysis and on intra- rather than interindividual variability, has enjoyed a steady resurgence in recent years, buttressed in large part by the ever-widening availability of analytically sophisticated modeling techniques for capturing dynamics in individual systems over time (Nesselroade, 2010; von Eye, Bergman, \& Hsieh, 2015).

To this resurgence of person-centered inquiry can now be added the important new work by Tafreshi, Khalil, and Racine featured in this issue. Their qualitative examination (via interpretative phenomenological analysis) of the particularities of eight women's beliefs about knowledge and knowing critically extends previous "personal epistemology" research by reconsidering orthodox group-level findings of gender differences from a person-centered, individualized vantage point. Their work reveals noteworthy variability in making sense of knowledge and learning among

\section{KARGER \\ E-Mail karger@karger.com www.karger.com/hde}

(c) 2018 S. Karger AG, Basel
David Witherington

Department of Psychology, University of New Mexico MSC03-2220

Albuquerque, NM 87131-1161 (USA)

E-Mail dcwither@unm.edu 
women who otherwise align in their characteristic domain or level of knowing (as indexed by the Women's Ways of Knowing measure). Despite being readily categorized as one kind of knower, for example, each of the eight women in Tafreshi et al.'s study demonstrated characteristics of multiple domains of knowing, suggesting that such domains are not mutually exclusive but compatible with one another. Tafreshi et al.'s paper serves as an elegant introduction to the topics of personal epistemology and of qualitative, person-oriented inquiry, cogently delineating person-oriented, qualitative analyses as complements to existing, aggregate-level (and quantitative) analyses in the literature.

As Tafreshi et al. themselves acknowledge, their current work serves as but a first step toward systematically framing, in person-centered terms, people's beliefs about knowledge and knowing. The extant literature on personal epistemology is not only largely confined to group-level characterizations and analyses, but also to cross-sectional studies of adults, a circumstance that significantly curtails insight into the actual developmental course and construction of personal epistemologies. By only capturing "epistemological development as one snapshot in time," Tafreshi et al.'s current work is likewise limited in the developmental implications that it can draw. Just as aggregate-level analyses fail to elucidate individual variation, so too do single time point, single context analyses of individuals fail to elucidate stability and variability within individuals across time and context, even within a given period of organizational stability in development.

Nonetheless, Tafreshi et al.'s paper usefully sets the stage for future person-centered investigations which will hopefully capitalize on much more extensive samples of intraindividual variation, across real time and context as well as across developmental time. And part of their paper's "stage setting" for future work is conceptual in nature. Tafreshi et al. specifically suggest that their study's results challenge (at least at the level of the individual) the basic conceptual framework that undergirds hierarchical stage models of epistemological development - a framework in which epistemological development "follows a singular developmental trajectory," "is independent of context," and in which later stages of personal epistemological development replace earlier stages by virtue of their increased "sophistication." The authors instead argue for a "situated," nonstage view of epistemological development. Such a view embraces both the potential for cultural and contextual variation in developmental sequencing of different knowing domains as well as the potential for coexistence of multiple knowing domains within any given period of developmental organization. Abandoned is the idea that some domains of knowing are more "sophisticated" than others, to be replaced by a conceptualization of different domains of knowing as local adaptations to different epistemic contexts.

Tafreshi et al. conclude their paper by acknowledging the possible heuristic value of hierarchical stage models "for making aggregate level comparisons" but also by cautioning that such models "do not necessarily speak to the complexity of individual experience." Their conclusion importantly promotes the utility of a multiperspectival approach, with consideration of the strengths and weaknesses that different levels of analysis in our scientific understanding of personal epistemology provide. However, their conclusion also tacitly accepts the ground rules within which conceptual debate in the personal epistemology literature has apparently been framed ground rules that effectively reduce hierarchical stage theory to its most reified and extreme conceptualization. I would therefore caution against seeing Tafreshi et al.'s 
work as a repudiation, writ large, of hierarchical stage theory's value at the level of individual experience; at best, their work demonstrates the limitations of a particular view of stage theory that itself has been largely discredited by many stage theory adherents. Instead, as the field of personal epistemology advances to extend Tafreshi et al.'s person-centered inquiry, it might behoove the field's investigators to reconsider hierarchical stage models of epistemological development through a broadened, more nuanced lens. With this in mind, I offer the following three points for consideration.

First, it is important to remember that a diversity of formulations is subsumed under hierarchical stage theory's aegis. Fifty years ago, Emmerich (1968) published a seminal examination of differential approaches, ipsative analyses, and hierarchical stage (or "classical development theory") approaches to personality development. In his discussion of classical developmental theory, Emmerich explicitly contrasted what he considered "the most radical case" of the hierarchical stage model, in which "attainment of a higher level fundamentally reorganizes and 'displaces' lower levels," with other, more moderate hierarchical stage models, in which "higher levels subsume earlier ones, but the latter remain active and quite capable of taking on a dominant role in normal functioning under certain circumstances" (p. 674). Generally speaking, more moderate hierarchical stage models - and their treatment of stage assignment as a relative designation, concerned with what kind of activity is most representative, modally speaking, of an individual - have supplanted radical stage treatments in developmental theory (Lerner, 2018). As a consequence, any challenge to the explanatory value of stage theory predicated solely on the basis of empirically invalidating its most radical incarnation treads dangerously closely to a straw man argument. Even if stage theoretical models of epistemological development embody such a radical incarnation, repudiation of such models at the level of individual experience does not in itself speak to the explanatory value of more moderate versions of hierarchical stage theory for understanding individual development.

Second, hierarchical stage theories of development have historically reflected organizational modes of explanation (e.g., formal and final "causes") characteristic of an organismic world view - modes of explanation that appeal to abstraction as a vital means of explanation in its own right (Lerner, 2018; Overton, 1991, 2015; Pepper, 1942; Reese \& Overton, 1970; Witherington, 2011). As an organizational mode of explanation, stages specifically abstract a patterning or general organization - a stage - from the variability that comprises a person's various activities across a multitude of contexts. This patterning has explanatory value precisely by virtue of abstracting an invariant characterization of the person, across time and context. Stage sequences embed the current, patterned understanding of a person's activities in terms of a sequence of qualitative reorganizations in the characteristic patterning of the person across developmental time, resulting in the abstraction of a directional sequence from an initial stage of developmental organization to an ideal "end stage" of developmental organization. Again, such diachronic patterning has explanatory value precisely by virtue of abstracting a developmental sequence within which any given level of characteristic patterning can be meaningfully framed.

When stages are viewed in this way - as an organizational mode of explanation, à la formal and final "causes" - the question of whether or not stage characterizations adequately account for contextual variability in an individual's activity and experience simply makes no sense. As abstractions, stage characterizations are necessarily 
abstracted away from the variability on which they are based and are therefore not designed to account for the particularities of such variability. This does not mean that hierarchical stage theorists - at least those who treat stages as organizational modes of explanation - view development as "independent of context." It merely means that they value the explanatory significance of organizational abstraction as a complement to any focus on the particularities of action in context. The practice of illuminating context-general regularities in people's functioning can be just as beholden to an appreciation for the thorough-going embeddedness of persons in sociocultural contexts as can the practice of illuminating context-specific particularities.

When appeals to stages are framed as functional explanations, however - such that stages become reified control structures "inside" an individual that antecede and initiate the individual's actions in the world - then stage theory is readily susceptible to precisely the sorts of challenges that Tafreshi et al. invoke. But such reified takes on stage theory mistakenly conflate organizational modes of explanation with antecedent-consequent modes of explanation, such as efficient and material causes, resulting in conceptual confusion (Chapman, 1988; Lourenco \& Machado, 1996). Classic criticisms of stage theory (e.g., Brainerd, 1978) have themselves been criticized for failing to recognize the conceptual distortion that classic stage theory undergoes when stages are improperly "viewed as the functional antecedents of age-related behaviors" (Chapman, 1988, p. 363).

Third, the idea that epistemological development "follows a singular developmental trajectory" does not in itself stand in opposition to a view of persons as thoroughly embedded in sociocultural context. Many classic hierarchical stage models assert an invariant ordering to stages not because these models ignore or actively neglect the importance of culture and context but because they are predicated on a theoretical conceptualization of certain prerequisite conditions (earlier stages) providing the necessary groundwork for future conditions (later stages) (Campbell \& Richie, 1983). The development of walking, for example, must necessarily follow, in sequential ordering, the development of standing, no matter the contextual circumstances of one's development, because walking ability first requires the ability to stand. In fact, many classic hierarchical stage models are essentially logical in their construction such that a later stage conceptually - and by definition - presupposes an earlier stage, rendering a reverse ordering of the two logically impossible. Take, for example, Bickhard's approach to cognitive development (or Piaget's approach to reflective abstraction) in which each subsequent stage of knowing in a hierarchy of levels of knowing is conceptualized as making explicit the implicit knowing ability of the preceding stage (Bickhard, 1978; Campbell \& Bickhard, 1986). Arguing for an invariant sequencing of stages is perfectly compatible with an embedding of development in context; it simply constitutes a focus on context-general regularities, rather than on context-specific particularities, within and across people in development. What is critical is how we, as scientists, arrive at those context-general regularities, not that we abstract such regularities. To the extent that we arrive at context-general regularities by first embracing variability in all of its forms - within and between individuals, across time and context - we are on solid scientific footing.

Once we situate our understanding of hierarchical stage theory in these broadened points of consideration, it should become clear that hierarchical stage theory is just as applicable to - and, in fact, fully compatible with - the level of person-centered inquiry as it is to an aggregate-level focus. In fact, for hierarchical stage theory to of- 
fer a developmentally legitimate explanatory frame, it should be built from longitudinal, person-centered inquiries, conducted in different sociocultural contexts, and not from aggregate-level analysis. Tafreshi et al.'s work constitutes an inspiring and instructive first step forward for such a person-oriented journey.

\section{References}

Bickhard, M. H. (1978). The nature of developmental stages. Human Development, 21(4), 217-233. doi: $10.1159 / 000271586$

Brainerd, C. J. (1978). The stage question in cognitive-developmental theory. Behavioral and Brain Sciences, 1(02), 173-182. doi:10.1017/S0140525X00073842

Campbell, R. L., \& Bickhard, M. H. (1986). Knowing levels and developmental stages. Basel, Switzerland: Karger. doi:10.1159/000272879

Campbell, R. L., \& Richie, D. M. (1983). Problems in the theory of developmental sequences. Human Development, 26(3), 156-172.doi:10.1159/000272879

Chapman, M. (1988). Constructive evolution: Origins and development of Piaget's thought. Cambridge, UK: Cambridge University Press.

Emmerich, W. (1968). Personality development and concepts of structure. Child Development, 39(3), 671-690. doi:10.2307/1126978

Lamiell, J. T. (2009). Reviving person-centered inquiry in psychology: Why its erstwhile dormancy? In J. Valsiner, P. C. M. Molenaar, M. C. D. P. Lyra, \& N. Chaudhary (Eds.), Dynamic process methodology in the social and developmental sciences (pp. 31-43). New York, NY: Springer. doi:10.1007/978-0-38795922-1_2

Lerner, R. M. (2018). Concepts and theories of human development (4th ed.). New York, NY: Routledge. doi:10.4324/9780203581629

Lourenço, O., \& Machado, A. (1996). In defense of Piaget's theory: A reply to 10 common criticisms. Psychological Review, 103(1), 143-164. doi:10.1037/0033-295X.103.1.143

Molenaar, P. C. M. (2004). A manifesto on psychology as idiographic science: Bringing the person back into scientific psychology, this time forever. Measurement: Interdisciplinary Research and Perspectives, 2(4), 201-218. doi:10.1207/s15366359mea0204_1

Nesselroade, J. R. (2010). On an emerging third discipline of scientific psychology. In P. C. M. Molenaar \& K. M. Newell (Eds.), Individual pathways of change: Statistical models for analyzing learning and development (pp. 209-218). Washington, DC: APA. doi:10.1037/12140-012

Nesselroade, J. R., \& Molenaar, P. C. M. (2010). Emphasizing intraindividual variability in the study of development over the life span: Concepts and issues. In W. F. Overton (Vol. Ed.) \& R. M. Lerner (Ed.in-Chief), The handbook of lifespan development: Cognition, biology, and methods. Vol. 1 (pp. 30-54). Hoboken, NJ: Wiley \& Sons.

Overton, W. F. (1991). The structure of developmental theory. In P. van Geert \& L. P. Mos (Eds.), Annals of theoretical psychology. Vol. 7 (pp. 191-235). New York, NY: Plenum Press. doi:10.1007/978-1-46153842-4_9

Overton, W. F. (2015). Processes, relations, and relational-developmental-systems. In W. F. Overton \& P. C. M. Molenaar (Vol. Eds.), \& R. M. Lerner (Ed.-in-Chief), Handbook of child psychology and developmental science. Vol. 1: Theory and method (7th ed., pp. 9-62). Hoboken, NJ: Wiley \& Sons. doi: 10.1002/9781118963418.childpsy102

Pepper, S. C. (1942). World hypotheses: A study in evidence. Berkeley, CA: University of California Press.

Reese, H. W., \& Overton, W. F. (1970). Models of development and theories of development. In L. R. Goulet \& P. B. Baltes (Eds.), Life-span developmental psychology: Research and theory (pp. 115-145). New York, NY: Academic Press. doi:10.1016/B978-0-12-293850-4.50011-X

Von Eye, A., Bergman, L. R., \& Hsieh, C. (2015). Person-oriented methodological approaches. In W. F. Overton \& P. C. M. Molenaar (Vol. Eds.), \& R. M. Lerner (Ed.-in-Chief), Handbook of child psychology and developmental science. Vol. 1: Theory and method (7th ed., pp. 789-841). Hoboken, NJ: Wiley \& Sons. doi:10.1002/9781118963418.childpsy121

Witherington, D. C. (2011). Taking emergence seriously: The centrality of circular causality for dynamic systems approaches to development. Human Development, 54(2), 66-92. doi:10.1159/000326814 